\title{
Penerapan Media Kartu KUPUBIL sebagai Pengayaan Materi Ujian Nasional Biologi
}

\author{
Fajar Adinugraha \\ Prodi Pendidikan Biologi, FKIP, Universitas Kristen Indonesia \\ Email korespondensi: fadinugraha@yahoo.co.id
}

doi: $10.29405 /$ j.bes/59-67121236

Received: 20 April 2018 | Accepted: 01 Juni 2018 | Published: 05 Juni 2018

\begin{abstract}
Abstrak
Tujuan: Penelitian ini bertujuan untuk mendeskripsikan bentuk dan cara permainan media kartu KUPUBIL (Kartu Untuk Persiapan Ujian Biologi). Selain itu, untuk mengamati hasil nilai Ujian Nasional Biologi setelah dilakukan eksperimen menggunakan kartu KUPUBIL. Penelitian ini juga untuk mengetahui persepsi peserta didik tentang kebermanfaatan kartu KUPUBIL. Jenis penelitian adalah pre experimental design. Metode: Desain penelitian adalah the one-shot case study design. Populasi dalam penelitian ini adalah siswa kelas XII MIPA SMA Citra Kasih Jakarta dengan sampel 12 siswa pemilih UNBK Biologi. Teknik pengambilan sampel menggunakan purposive random sampling. Bentuk kartu KUPUBIL berjumlah 96 buah dengan ukuran 7,5 cm x $11 \mathrm{~cm}$. Kartu berisi gambar-gambar yang sering keluar di soal Ujian Nasional. Permainan kartu ini dimodifikasi dari permainan kartu pada umumnya. Hasil: Hasil menunjukkan bahwa media kartu ini mampu meningkatkan nilai Ujian Nasional. Nilai Try Out 6 (sebelum perlakuan) yaitu 67,92 sedangkan nilai Ujian Nasional (sesudah perlakuan) yaitu 73,75. Persepsi peserta didik terhadap kebermanfaatan media kartu ini adalah sangat positif. Hal ini ditunjukkan dari hasil wawancara kepada responden yang memberikan apresiasi dan merasakan manfaat dari media kartu KUPUBIL. Kesimpulan: Media pembelajaran kartu KUPUBIL dapat digunakan sebagai altenatif media pembelajaran dalam mempersiapkan Ujian Nasional Biologi.
\end{abstract}

Kata kunci: Kartu KUPUBIL; Program Pengayaan; Ujian Nasional Biologi

\begin{abstract}
Background: This study aims to describe the shape and manner of KUPUBIL (Card For Examination Biology) game card. In addition, to observe the results of National Biological Examination score after experimenting using KUPUBIL card. This research is also to know the perception of learners about the utilization of KUPUBIL card. The type of research is pre-experimental design. Methods: The research design is the one-shot case study design. The population in this study is the students of grade XII MIPA SMA Citra Kasih Jakarta with a sample of 12 students of UNBK Biology voters. The sampling technique used purposive random sampling. The form of KUPUBIL card amounted to 96 pieces with the size of $7.5 \mathrm{~cm}$ $\mathrm{x} 11 \mathrm{~cm}$. The card contains pictures that often come out in the matter of National Exam. This card game is modified from card games in general. The results show that the media card was able to increase the value of National Exam. The value of Try Out 6 (before treatment) was 67.92 while the National Examination (after treatment) was 73.75. The learner's perception of the usefulness of this card media was very positive. It was shown from the interview to respondents who give appreciation and feel the benefits of KUPUBIL card media. Conclusions: KUPUBIL card learning media can be used as an alternative media learning in preparing the National Examination of Biology.
\end{abstract}

Keywords: Media Development, Android, Mobile Learning, Learning Media 


\section{PENDAHULUAN}

Mulai tahun 2015, nilai Ujian Nasional (UN) bukan sebagai satu-satunya penentu kelulusan. Kelulusan peserta didik dilihat dari nilai rapor dan USBN (Ujian Sekolah Berstandar Nasional). Meskipun demikian, Ujian Nasional masih menjadi hal yang ditakutkan oleh sebagian peserta didik. Hal ini dapat dilihat dari meningkatnya kegiatan les privat atau bimbingan belajar menjelang UN. Tentunya, hal ini masih dapat dipandang sebagai sesuatu yang positif, karena peserta didik masih memiliki niat untuk memperdalam ilmu. Terlepas dari kontroversi Ujian Nasional, penulis mencari sisi positif dan manfaatnya. Menurut Mardapi (2009), Ujian nasional memberikan dampak positif antara lain: 1) motivasi belajar siswa menjadi tinggi, 2) guru termotivasi untuk mengajar lebih baik, dan 3) orang tua siswa semakin peduli terhadap anaknya.

Permasalahan yang ditakutkan adalah bahwa peserta didik menjadi stress karena materi UN terlalu banyak. Seharusnya, peserta didik mampu melewati masalah ini. Hal ini seperti yang dikatakan oleh Gubernur NTB (Muhammad Zainul Majdi) dalam seminar kebangsaan di Universitas Kristen Indonesia (28 Oktober 2017), yang mengatakan bahwa apabila kita keras terhadap diri sendiri, akan terbentuk generasi yang tangguh di masa depan.

Tentunya, masalah materi UN yang banyak dan sulit, dapat dicarikan solusi melalui cara yang tepat. Materi UN Biologi yang sangat banyak, serta kisi-kisi yang diberikan sangat luas mengakibatkan peserta didik bingung dan malas untuk mempelajarinya. Selain itu, salah satu masalah yang dihadapi peserta didik adalah kesulitan mengingat ketika mengerjakan soal yang berisi mengenai gambar atau skema (Mu'minah, 2017).

Setiap tahunnya, soal UN ada sekitar 4 sampai 5 paket yang berbeda. Soal yang berisi gambar pun jumlahnya berbeda setiap tahunnya. Pada tahun 2013 hingga 2016 terdapat 11-15 soal yang menggunakan gambar dalam soal. Apabila dipersentasekan sekitar 27,5\% sampai 37,5\%.

Di dalam memahami gambar yang banyak, peserta didik terkadang tertukar pemahaman konsepnya. Oleh karena itu, diperlukan sebuah media pembelajaran yang berisi gambar-gambar mengenai soal yang sering keluar di Ujian Nasional. Media pembelajaran ini tentunya dibuat agar peserta didik lebih mudah memahami materi dan tidak bosan dalam menghafal serta memahami gambar.

Menurut Danim (1995) dalam Mahnun (2012), media pembelajaran merupakan sarana penyalur pesan atau informasi belajar yang hendak disampaikan oleh sumber pesan kepada sasaran atau penerima pesan tersebut. Penggunaan media pembelajaran dapat membantu pencapaian keberhasilan belajar. Salah satu media pembelajaran yang mudah dibuat dan mudah digunakan adalah kartu belajar bergambar (Amirullah \& Susilo, 2018).

Bermain kartu memang hal yang mengasyikkan bagi peserta didik. Namun, perlu dibuat sebuah kartu yang di dalamnya memuat pembelajaran Biologi. Menurut hasil penelitian Na'ima (2014), media kartu dapat memotivasi peserta didik dalam belajar. Belajar dengan penuh motivasi akan memberikan energi yang positif dalam pembelajaran. Energi yang positif ini diharapkan dapat mempengaruhi nilai Ujian Nasional.

Berdasarkan hal tersebut, dibuatlah kartu belajar dengan nama Kartu KUPUBIL. KUPUBIL merupakan singkatan dari Kartu Untuk Persiapan Ujian Biologi. Kartu ini berisi gambar-gambar yang berkaitan dengan Ujian Nasional Biologi seperti siklus hidup, daur biogeokimia, jaringan, sel, sistem organ, fotosintesis, evolusi, dan sebagainya.

Kartu KUPUBIL ini dibuat karena melihat nilai hasil Try Out Ujian Nasional Biologi di 
kelas XII SMA Citra Kasih Jakarta, pada bulan November sampai Januari yang berada di bawah nilai 70 (kategori C). Padahal sebelumnya nilai rerata UN Biologi yaitu 76,9. Salah satu faktor yang menyebabkan adalah pada tahun 2017, peserta didik hanya diperbolehkan untuk memilih salah satu dari mata pelajaran IPA. Dari 25 siswa kelas XII, sebanyak 12 siswa memilih Fisika, 1 siswa memilih Kimia, dan 12 siswa memilih Biologi. Awalnya, pemilih UN Biologi adalah 7 siswa. Namun, karena pertimbangan nilai di Fisika dan Kimia, peserta didik yang memilih Fisika dan Kimia dilimpahkan ke Biologi. Hal ini karena peserta didik tersebut lemah di perhitungan Fisika dan Kimia. Padahal, nilai di Biologi peserta didik yang pindah tersebut juga tidak bagus. Alhasil, hanya sekitar 5 siswa dari 12 siswa yang memiliki minat dan kompetensi yang cukup di Biologi.

Namun, hal itu menjadikan tantangan bagi penulis untuk mengatasi permasalahan tersebut. Kesulitan utama yang dihadapai peserta didik tersebut adalah bingung ketika mengerjakan soal bergambar. Oleh karena itu, diperlukan media belajar kartu bergambar KUPUBIL untuk mengatasi masalah tersebut. Artikel ini membahas mengenai: 1) Bagaimana bentuk permainan kartu KUPUBIL, 2) Bagaimana hasil nilai UN Biologi 2017 SMA Citra Kasih Jakarta, dan 3) Bagaimana persepsi peserta didik tentang manfaat kartu KUPUBIL?

\section{MATERI DAN METODE}

\section{Lokasi dan waktu penelitian}

Penelitian ini dilaksanakan dari bulan November 2016 - Juni 2017. Pada bulan November - Desember 2016 dilakukan observasi. Bulan Januari 2017 dilakukan pembuatan kartu KUPUBIL. Bulan Februari hingga Maret 2017 dilakukan eksperimen. Bulan April - Mei dilakukan pengambilan data. Tempat penelitian di SMA Citra Kasih Jakarta tahun akademik 2016/2017.

\section{Desain penelitian}

Jenis penelitian ini adalah pre eksperimental design dengan rancangan the oneshot case study. Desain penelitian dapat diilihat pada tabel 1 sebagai berikut.

Tabel 1. Desain penelitian

\begin{tabular}{lc}
\hline $\mathrm{X}$ & $\mathrm{O}$ \\
\hline $\begin{array}{c}\text { Treatment of } \\
\text { independent variable }\end{array}$ & $\begin{array}{c}\text { Observation or } \\
\text { measurement of } \\
\text { dependent variable }\end{array}$ \\
\hline Keterangan \\
$\mathrm{X} \quad$ = penerapan kartu KUPUBIL \\
$\mathrm{O} \quad=$ observasi nilai UN dan persepsi \\
peserta didik
\end{tabular}

\section{Populasi dan sampel}

Populasi dalam penelitian ini adalah peserta didik kelas XII MIPA SMA Citra Kasih Jakarta. Sampel dalam penelitian ini adalah 12 peserta didik kelas XII. Pengambilan sampel didasarkan pada pemilih UNBK Biologi 2017 di SMA Citra Kasih Jakarta.

\section{Teknik Pengumpulan Data}

Pengambilan data dapat dijelaskan sebagai berikut.

1. Data bentuk permainan kartu KUPUBIL.

Data ini diambil dengan cara mendeskripsikan: 1) bentuk fisik kartu KUPUBIL dan 2) cara memainkan kartu KUPUBIL.

2. Data hasil nilai UN Biologi 2017 SMA Citra Kasih Jakarta.

Data ini diambil dengan melihat perkembangan nilai Try Out setelah diberi perlakuan hingga nilai Ujian Nasional Biologi yang dilaksanakan di bulan April 2017. Soal Try Out dan UN Biologi terdiri dari 40 soal pilihan ganda, dengan materi dari kelas X hingga kelas XII.

3. Data persepsi perserta didik tentang manfaat kartu KUPUBIL

Data ini diambil dengan melakukan wawancara dengan 5 butir pertanyaan seperti disajikan pada Tabel 2 di bawah ini. 
Tabel 2. Kisi-kisi pertanyaan persepsi peserta didik tentang manfaat kartu KUPUBIL

\begin{tabular}{cl}
\hline Nomor & Kisi-kisi pertanyaan \\
\hline 1 & Kecemasan Ujian Nasional Biologi \\
2 & Daya ingat materi dan pemahaman \\
3 & Kelebihan kartu KUPUBIL \\
4 & Kekurangan kartu KUPUBIL \\
5 & Kebermanfaatan kartu KUPUBIL \\
\hline
\end{tabular}

\section{Teknik Analisis Data}

Selanjutnya, setelah data terkumpul. Data tersebut dianalisis sebagai berikut.

1. Data bentuk permainan kartu KUPUBIL. Data ini dianalisis secara deskriptif dengan memaparkan bentuk fisik kartu KUPUBIL dan cara memainkan kartu tersebut.

2. Data hasil nilai UN Biologi 2017 SMA Citra Kasih Jakarta.

Data ini dianalisis secara kualitatif dengan membuat rata-rata (mean) dari nilai peserta didik tiap Try Out dan Ujian Nasional. Data tersebut dibuat dalam diagram batang. Selanjutnya, data dideskripsikan dan dikaitkan dengan teori atau penelitian sejenis sebelumnya.

3. Data persepsi perserta didik tentang manfaat kartu KUPUBIL

Data ini dianalisis secara deskriptif dengan merangkum hasil wawancara terhadap responden.

\section{HASIL}

Penerapan media kartu KUPUBIL (Kartu Untuk Persiapan Ujian Biologi) dilaksanakan pada akhir Februari hingga awal April sebelum Ujian Nasional. Sebelum kartu KUPUBIL ini dibuat, rerata Try Out bulan November hingga Januari selalu di bawah 70 atau berada pada kategori C. Data dapat dilihat pada gambar 1.

Pada bagian ini akan membahas tiga hasil penelitian, yaitu: 1) bentuk permainan kartu KUPUBIL, 2) hasil ujian nasional Biologi, dan 3) persepsi peserta didik tentang manfaat kartu KUPUBIL.

\section{Bentuk kartu KUPUBIL}

Kartu KUPUBIL terdiri dari 96 kartu bergambar. Setiap kartu terdapat gambar yang berhubungan dengan soal Ujian Nasional. Kartu berukuran $7 \mathrm{~cm}$ x $11,5 \mathrm{~cm}$. Kartu dicetak menggunakan kertas jenis BW. Di ujung kanan atas kartu, terdapat warna merah, oranye, kuning, dan hijau. Warna ini digunakan sebagai tingkatan dalam kartu. Warna merah $>$ warna oranye $>$ warna kuning $>$ warna hijau. Jadi, warna ini digunakan untuk memodifikasi permainan. Bentuk kartu dapat dilihat pada Gambar 2.

Media kartu KUPUBIL ini dimainkan dengan tahapan sebagai berikut.

a. Penerapan media kartu KUPUBIL.

Penerapan media ini dilaksanakan saat pembelajaran Biologi, bisa dilakukan 45-80 menit tergantung kondisi kelas.

b. Try Out

Try Out dilaksanakan berdasarkan jadwal sekolah, jadwal dinas, atau jadwal mandiri. Untuk validasi soal Try Out tidak dilakukan karena soal tersebut adalah soal yang sudah ada di bank soal dan beberapa diberikan oleh Dinas Pendidikan sehingga tidak dilakukan validasi. Demikian juga, soal Ujian Nasional adalah soal dari pemerintah pusat sehingga sudah dilakukan telaah yang mendalam.

c. Pembahasan Try Out

Setelah dilakukan Try Out, pada pertemuan selanjutnya dilakukan pembahasan terhadap soal Try Out. Pembahasan selalu dilakukan agar peserta didik mengerti kesalahan dalam mengerjakan soal. 


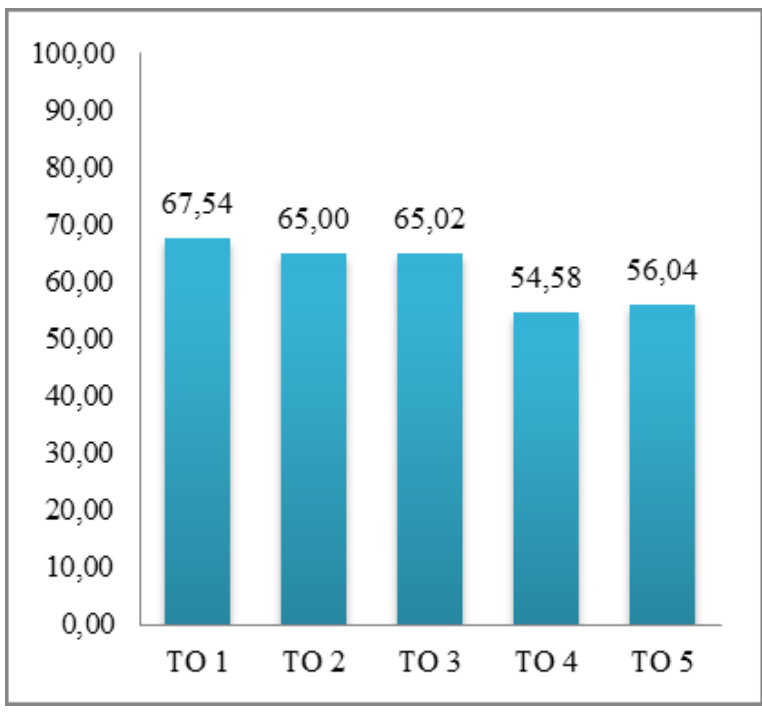

Gambar 1. Rata-rata Try Out bulan November 2016 hingga Januari 2017.

\section{Hasil nilai UN Biologi 2017 SMA Citra Kasih Jakarta.}

Setelah dilaksanakan Try Out 1 sampai 5 (bulan November 2016 hingga Januari 2017), maka dilakukan eksperimen dengan diterapkannya media pembelajaran kartu KUPUBIL terhadap kelas XII SMA Citra Kasih Jakarta.

Data diambil dari nilai Try Out 6 (sebelum perlakuan) dan data nilai Ujian Nasional 2017 (sesudah perlakuan). Namun, data nilai setiap Try Out tetap dipantau untuk mengetahui perkembangannya. Hal ini karena sangat tidak mungkin ketika sebuah media pembelajaran diterapkan sekali langsung dapat memberikan dampak yang optimal. Oleh karena itu, dilakukan pemantauan perkembangan nilai seperti disajikan Gambar 3. Pada gambar 3, dapat dilihat terjadi peningkatan nilai Try Out 6 (sebelum perlakuan) dan nilai Ujian Nasional 2017 (sesudah perlakuan). Untuk melihat data perbedaan nilai lebih jelas, maka disajikan tabel 4.

\section{Persepsi peserta didik tentang manfaat kartu KUPUBIL.}

Data terakhir yang diambil adalah persepsi peserta didik tentang manfaat kartu KUPUBIL. Pengambilan data ini dilakukan dengan wawancara tertutup yang terdiri dari 5 pertanyaan. Wawancara dilakukan kepada 12 responden setelah peserta didik mendapatkan nilai hasil Ujian Nasional. Media kartu KUPUBIL ini mendapatkan persepsi sangat positif bagi perserta didik.
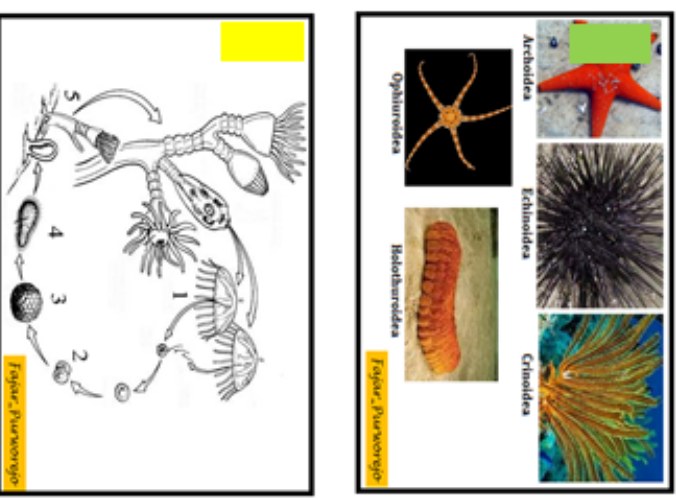

Gambar 2 Bentuk kartu KUPUBIL. 


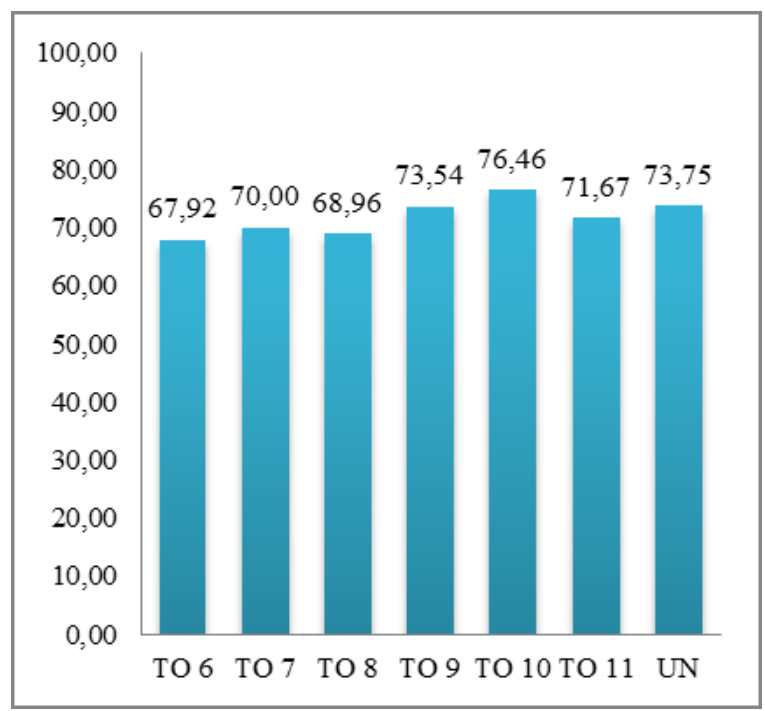

Gambar 3 Rata-rata Try Out 6 hingga UN Biologi 2017.

\section{PEMBAHASAN}

\section{Bentuk kartu KUPUBIL}

Permainan kartu KUPUBIL ini sebenarnya merupakan modifkasi dari permainan kartu yang ada pada umumnya. Ada beberapa alternatif permainan kartu agar tidak membosankan. Berikut macam-macam permainan kartu yang menggunakan kartu KUPUBIL

a. Tebak kartu

Sebagai tahap awal pengenalan gambar di kartu, dilakukan permainan tebak kartu. Caranya sebagai berikut:

- Kartu dikocok dan ditumpuk di tengah.

- Peserta didik duduk mengelilingi kartu.

- Seorang peserta didik mengambil satu kartu kemudian menjelaskan gambar kartu tersebut.
- Apabila tidak bisa menjawab kartu tersebut di simpan.

- Kemudian dilakukan secara bergantian dengan peserta lain.

- Peserta didik yang paling banyak menyimpan kartu, dialah yang kalah.

Pada permainan tebak kartu, dibutuhkan guru atau peserta didik yang memiliki pengetahuan mengenai gambar-gambar kartu tersebut. Jika ada peserta didik yang tidak tahu atau salah menjawab, maka bisa segera diberi tahu. Apabila peserta didik dirasa sudah lancar memahami gambar-gambar kartu, maka bisa dilakukan modifikasi permainan kartu.

b. Minuman

Permainan ini menggunakan syarat bahwa kartu memiliki tingkatan nilai.

Tabel 3.Nilai sebelum perlakuan dan sesudah perlakuan siswa.

\begin{tabular}{lll}
\hline Sumber Variasi & $\begin{array}{l}\text { Sebelum perlakuan } \\
(\text { Try Out 6) }\end{array}$ & $\begin{array}{l}\text { Sesudai perlakuan } \\
\text { (UN 2017) }\end{array}$ \\
\hline Jumlah Siswa & 12 & 12 \\
Nilai rata-rata & 67,92 & 73,75 \\
Nilai tertinggi & 90,00 & 85,00 \\
Nilai terendah & 52,50 & 62,50 \\
Jumlah siswa tuntas $(>55)$ & 11 & 12 \\
Jumlah siswa tidak tuntas $(<55)$ & 1 & 0 \\
\hline
\end{tabular}


Secara berurutan dari besar ke kecil yaitu merah $>$ oranye $>$ kuning $>$ hijau. Caranya sebagai berikut:

- Kartu dikocok kemudian dibagikan masingmasing 5 kartu sama rata kepada peserta didik

- Peserta didik yang mengkocok kartu mengeluarkan satu kartu.

- Kemudian, peserta lain juga mengeluarkan kartu. Jika kartu yang dikeluarkan peserta didik warnaya paling lemah, maka peserta didik tersebut harus menjawab gambar di kartu tersebut. (Bila terjadi warna yang sama maka bisa dilakukan suit)

- Jika peserta didik tersebut tidak bisa menjawab, maka kartu tersebut diambil oleh peserta didik.

- Peserta didik yang paling akhir menghabiskan kartu, dialah yang kalah.

\section{c. Modifikasi lima satu}

Permainan ini mengunakan syarat bahwa peserta didik harus mengumpulkan warna yang sama sebanyak 5 kartu. Misalnya, mengumpulkan warna merah semua atau hijau semua, tinggal dipilih salah satu. Caranya sebagai berikut:

- Kartu diocok dan dibagikan kepada kepada peserta didik sebanyak 5 kartu.

- Kartu sisa diletakkan di bagian tengah peserta

- Secara bergantian, peserta didik mengambil satu kartu di tumpukan kartu untuk mencari warna yang sama.

- Apabila tidak ingin diambil, maka kartu harus dibuang ke sebelah kanan peserta didik lainnya.

- Apabila ingin diambil kartunya, maka kartu lain harus tetap dibuang. Jadi, masingmasing peserta didik tetap memegang lima kartu.

- Peserta didik yang paling akhir mengumpulkan kartu, dialah yang kalah.
- Peserta didik yang kalah, diminta untuk menjelaskan kartu - kartu sesuai kesepakatan pemain.

Pada dasarnya, kartu KUPUBIL ini bisa dimainkan dengan modifikasi lain seperti tepok nyamuk, kartu setan, dan sebagainya. Permainan kartu ini bukan bermaksud untuk mengajari peserta didik bertindak negatif. Namun, dapat diambil sisi positif dari bermain kartu KUPUBIL yaitu untuk memahami materi dengan menyenangkan dan tidak membosankan. Kartu KUPUBIL ini bisa digunakan untuk menghilangkan rasa jenuh di tengah Try Out yang banyak menjelang Ujian Nasional.

\section{Hasil nilai UN Biologi 2017 SMA Citra Kasih Jakarta.}

Pada tabel 4 disajikan perbedaan nilai Ujian Nasional 2017 (sesudah perlakuan) yang menjadi lebih baik nilainya dibanding nilai Try Out 6 (sebelum perlakuan). Terjadi peningkatan sekitar 5,83 poin dari sebelumnya. Peningkatan yang terjadi memang di bawah 10 poin. Namun, bagi penulis yang sekaligus menjadi guru, ini merupakan hal yang baik. Hal ini mengingat kondisi kemampuan nilai Biologi tidak begitu baik untuk beberapa siswa.

Terjadi penurunan untuk nilai tertinggi yaitu 5 poin. Namun, terjadi kenaikan nilai 10 poin untuk nilai terendah. Semua peserta didik mendapatkan nilai ketuntasan minimum ujian nasional yaitu $>55$.

Menurut Sutijono (2005) dalam Machin (2012), keberhasilan penggunaan media dalam pembelajaran untuk meningkatkan hasil belajar tergantung isi pesan, cara menjelaskan pesan dan karakteristik penerima pesan. Tidak berarti bahwa semakin canggih media yang digunakan akan semakin tinggi hasil belajar atau sebaliknya. Kartu KUPUBIL dapat dibuat dengan mudah dan murah. Gambar-gambar yang berkaitan dengan 
soal UN Biologi banyak ditemukan di mesin pencari google ataupun bank soal. Media kertas juga relatif murah dan mudah dibuat di percetakan.

\section{Persepsi peserta didik tentang manfaat kartu KUPUBIL}

Wawancara pertama mengenai kecemasan mengenai Ujian Nasional setelah belajar menggunakan kartu KUPUBIL. Semua responden mengatakan bahwa kecemasan responden berkurang setelah bermain menggunakan kartu ini. Kecemasan berkurang karena ada 2 hal, yaitu: 1) dengan bermain, responden merasa lebih santai dan 2) dengan mengulas materi lewat kartu, responden merasa percaya diri dengan soal ujian yang akan dihadapi.

Wawancara kedua mengenai daya ingat materi Biologi. Semua responden mengatakan bahwa dengan bermain menggunakan kartu KUPUBIL membuat responden lebih mudah mengingat materi. Hal ini karena permainan dilakukan berulang-ulang sehingga responden akan melihat gambar yang sama dan berusaha untuk memahaminya.

Wawancara ketiga mengenai kelebihan kartu KUPUBIL. Semua responden memberikan tanggapan yang baik terhadap kartu ini. Kelebihan dari kartu KUPUBIL menurut responden, yaitu: 1) membuat responden lebih mudah mengerti secara detail; 2) menyenangkan dan tidak membuat responden stress; 3) mudah dipakai karena bisa dimainkan bersama dan aturan main seperti permainan kartu biasa; dan 4) unik, ini kali pertama responden melihat pembelajaran menggunakan kartu.

Wawancara keempat mengenai kekurangan kartu KUPUBIL. Beberapa responden memberikan saran antara lain: 1) jumlah kartu sedikit yaitu 96 buah,sehingga tidak memenuhi semua gambar di materi Biologi dan 2) bahan kartu kurang keras sehingga tidak mantab ketika memainkannya.

$$
\text { Wawancara kelima mengenai }
$$

kebermanfaatan kartu KUPUBIL. Semua responden mengatakan bahwa kartu KUPUBIL ini memberikan manfaat bagi responden. Responden berargumen bahwa kartu ini membantu siswa yang sulit menghafal karena isi kartu mengandung materi Ujian Nasional. Bahkan, ada responden yang mengatakan bahwa dengan kartu KUPUBIL membuat responden optimis sehingga menghasilkan nilai di atas 55 .

Dalam pembuatan media pembelajaran harus bervariasi, menarik perhatian dan menyenangkan, dapat memberikan pengalaman belajar sehingga peserta didik dapat menangkap materi pembelajaran dengan mudah (Primasari, 2014). Media kartu KUPUBIL mendapat respon positif dari peserta didik karena memberikan manfaat dalam mempersiapkan Ujian Nasional dengan suasana yang menyenangkan. Dalam suasana hati yang senang, materi pelajaran lebih mudah dipahami.

Sesuai dengan pernyataan Musfiqon (2012) dalam Nurlatipah (2015), yang mengatakan bahwa media pembelajaran merupakan alat bantu yang berfungsi untuk menjelaskan sebagian dari keseluruhan program pembelajaran yang sulit dijelaskan secara verbal. Menurut Adinugraha (2017), dalam pembuatan media pembelajaran perlu dimiliki pengetahuan akademik mengenai materi yang akan digunakan dalam pembuatan media pembelajaran. Setelah itu, diperlukan adanya kreativitas untuk membuat media pembelajaran tersebut.

\section{KESIMPULAN}

Media pembelajaran kartu KUPUBIL (Kartu Untuk Persiapan Ujian Biologi) dapat digunakan sebagai alternatif media pembelajaran dalam mempersiapkan Ujian Nasional Biologi. 
1. Media pembelajaran kartu KUPUBIL berisi gambar-gambar yang berhubungan dengan soal Ujian Nasional Biologi SMA.

2. Media pembelajaran kartu KUPUBIL dapat meningkatkan nilai siswa. Peningkatan ini dilihat dari nilai Try Out 6 (sebelum perlakuan) yaitu 67,92 menjadi 73,75 yaitu nilai Ujian Nasional Biologi (sesudah perlakuan).

3. Media kartu KUPUBIL ini mendapatkan persepsi sangat positif bagi peserta didik. Peserta didik merasakan manfaat menggunakan kartu KUPUBIL.

\section{DAFTAR PUSTAKA}

Adinugraha, F. 2017. Media pembelajaran biologi berbasis ecopreneurship. Jurnal Pro - Life. Vol. 7 (3): $219-233$.

Amirullah, G., \& Susilo, S. (2018). Pengembangan Media Pembelajaran Interaktif Pada Konsep Monera Berbasis Smartphone Android. Wacana Akademika, 2(1), 38-47.

Arikunto, S. 2010. Prosedur penelitian suatu pendekatan praktik. Rineka Cipta. Jakarta.

Arsyad, A. 2002. Media Pembelajaran. Raja Grafindo. Jakarta.

Machin, A. 2012. Pengaruh Permainan Call Cards Terhadap Hasil Belajar dan Aktivitas Pembelajaran Biologi. Jurnal Pendidikan IPA Indonesia. Vol. 1 (2): 163-167.

Manun, N. 2012. Media Pembelajaran (Kajian terhadap Langkah-Langkah Pemilihan Media dan Implementasinya dalam Pembelajaran. Jurnal Pemikiran Islam. Vol. 37 (1): 27-33.

Mardapi, D., \& Badrun, K. 2009. Dampak Ujian Nasional. Laporan penelitian Program Pascasarjana UNY. On line at http://staff.uny.ac.id/sites/default/files/6Dampak\%20Ujian\%20Nasional.pdf [diakses 2 September 2017, 14:00].

Mu'minah, I. H. (2017). Uji Coba Penerapan Model Pembelajaran Kooperatif Tipe Tim Games Tournament pada Konsep Sistem Pencernaan Makanan pada Manusia Di Kelas XI IPA MAN Tasikmalaya. Jurnal Bioeduscience, 1(1), 06. doi:10.29405/bioeduscience/06-10111080

Na'ima, QA., Darlen, S., \& Afif, B. 2014. Pengaruh Penggunaan Media Kartu Kuartet terhadap Motivasi dan Hasil Belajar Siswa. Jurnal Bioterdidik. Vol. 2 (10): 1-11.
Nurlatipah, N., Anda, J., \& Yuyun, M. 2015. Pengemabangan Media Pembelajaran Komik Sains yang Disertai Foto untuk Meningkatkan Hasil Belajar Siswa Kelas VII SMP N2 Sumber Pokok Bahasan Ekosistem. Jurnal Scientiae Educatia, Vol. 5 (2): 1-13.

Primasari, R., Zulfiani., \& Yanti H. 2014. Penggunaan Media Pembelajaran di Madrasah Aliah Negeri se Jakarta Selatan. Jurnal Edusains. Vol. 6 (1) : 6872.

Supardi, U.S. 2013. Aplikasi statistika dalam penelitian edisi revisi. Change Publication. Jakarta.

Yudhi, M. 2008. Media pembelajaran: sebuah pendekatan baru. Gaung Persada Press. Jakarta. 